\title{
Composition analysis of boron carbide coatings prepared by reactive sputtering with nitrogen
}

Jiali Wu, Qiushi Huang, Runze Qi, Yufei Feng, Zhanshan Wang

Jiali Wu, Qiushi Huang, Runze Qi, Yufei Feng, Zhanshan Wang, "Composition analysis of boron carbide coatings prepared by reactive sputtering with nitrogen," Proc. SPIE 11886, International Conference on X-Ray Lasers 2020, 118860V (8 July 2021); doi: $10.1117 / 12.2593360$ 


\title{
Composition analysis of boron carbide coatings prepared by reactive sputtering with nitrogen
}

\author{
Jiali Wu, ${ }^{\mathrm{a}, \mathrm{b}}$, Qiushi Huang ${ }^{\mathrm{a}, \mathrm{b}}$, Runze Qi ${ }^{\mathrm{a}, \mathrm{b}}$, Yufei Feng ${ }^{\mathrm{a}, \mathrm{b}}$, Zhanshan Wang ${ }^{\text {,a,b }}$ \\ ${ }^{a}$ MOE Key Laboratory of Advanced Micro-Structured Materials, No. 1239 Siping Road 200092, \\ Shanghai, China \\ ${ }^{\mathrm{b}}$ Institute of Precision Optical Engineering, School of Physics Science and Engineering, Tongji \\ University, Shanghai 200092, China \\ *Corresponding author: wangzs@ tongji.edu.cn
}

\begin{abstract}
Boron carbide coatings were prepared by reactive sputtering with nitrogen and investigated for their optical properties. Different ratios of $\mathrm{N}_{2} / \mathrm{Ar}(4 \%, 8 \%$, and $15 \%$ nitrogen ratio) mixture gas was chosen as the sputtering gas. The atomic concentration distribution and elemental chemical states of coatings were characterized by X-ray photoelectron spectroscopy measurements. The B/C ratio was 3.7:1 and the nitrogen content was 18 at.\% in the coating, which was sputtered with $4 \% \mathrm{~N}_{2}$ mixture gas. And the nitrogen content was increased as the ratio of $\mathrm{N}_{2}$ increases in mixture gas. In the nitridated $\mathrm{B}_{4} \mathrm{C}$ coatings, the boron mainly existed as the formation of $\mathrm{BN}$ and $\mathrm{B}_{4} \mathrm{C}$ compounds. The theoretical reflectivity was performed, and the increase of nitrogen content would reduce the reflectivity in the soft X-ray, especially in the vicinity of $410 \mathrm{eV}$.
\end{abstract}

Keywords: Boron carbide, reactive sputtering, nitrogen

\section{INTRODUCTION}

X-ray mirrors are important optical elements in synchrotron radiation, free-electron lasers, and other advanced light sources [1]. Based on total external reflection, X-ray mirror can achieve high reflectivity under critical angle of grazing incidence. Boron carbide $\left(\mathrm{B}_{4} \mathrm{C}\right)$ is an excellent material with high hardness, high damage threshold, and low absorption coefficient in EUV and X-ray range [2-4]. In LCLS, $\mathrm{B}_{4} \mathrm{C}$ coating mirrors have been applied in 0.827-2 keV soft X-ray band [5]. In SwissFEL, $\mathrm{B}_{4} \mathrm{C} / \mathrm{SiC}$ bilayer mirrors are equipped to maintain high reflectivity up to $12.4 \mathrm{keV} \mathrm{[6-7].}$

$\mathrm{B}_{4} \mathrm{C}$ coatings deposited at low pressure presented a large compressive stress about $-3 \mathrm{GPa}$ [8]. Control of stress can be achieved by means of different deposition conditions such as sputtering pressure, reactive sputtering, annealing and bias voltage [9-11]. Soufli $\mathrm{R}$. et al. investigated the structure and optiof 50-nm thick $\mathrm{B}_{4} \mathrm{C}$ coating under 10 mTorr argon pressure. $\mathrm{B}_{4} \mathrm{C}$ coating under high pressure have the low stress with $-1.1 \mathrm{GPa}$ and accepted roughness with $0.47 \mathrm{~nm}$ [12]. In study of $\mathrm{W} / \mathrm{B}_{4} \mathrm{C}$ multilayers, Windt $\mathrm{D}$. deposited $\mathrm{B}_{4} \mathrm{C}$ coatings by reactive sputtering with nitrogen. The coatings presented the low stress below -1 GPa and low roughness [13]. However, it did not specifically analyze the elemental valence and optical properties of coatings.

The detailed atomic structure of B-C-N has been previously studied in several literatures. Laidani N. et al. studied the composition analysis of B-C-N coatings deposited by laser reactive ablation of the $\mathrm{B}_{4} \mathrm{C}$ target in low-pressure (5 Pa) $\mathrm{N}_{2}$ atmosphere and found that no B-C bonds were formed [14]. Bengu E. et al. synthesized the B-C-N coatings deposited by $\mathrm{RF}$ sputtering. XPS results show that for B-C-N coatings with grounded and $-600 \mathrm{~V}$ bias setting. In the B $1 \mathrm{~s}$ spectrum, the main fitting peak was aimed to B-N bonds, only weak B-O bonds and B-C bonds were observed [15].

International Conference on X-Ray Lasers 2020, edited by Davide Bleiner,

Proc. of SPIE Vol. 11886, 118860V · (C) 2021 SPIE · CCC code:

$0277-786 \mathrm{X} / 21 / \$ 21 \cdot$ doi: $10.1117 / 12.2593360$

Proc. of SPIE Vol. 11886 118860V-1 
In application of mirrors in FELs, $\mathrm{B}_{4} \mathrm{C}$ coating mirror deposited by reactive sputtering with nitrogen haven't taken into account. Based on the advantages of reactive sputtering technology, it is worth further studying the $\mathrm{B}_{4} \mathrm{C}$ coatings prepared by reactive sputtering with nitrogen. In our previous work [16], $\mathrm{B}_{4} \mathrm{C}$ coatings deposited by reactive sputtering were prepared and showed low surface roughness and low stress. It was consistent with the results of David Windt [13]. As the $\mathrm{N}_{2}$ ratio of $4 \%$, the coating stress sharply decreased from -3 GPa to $-1 \mathrm{GPa}$. The roughness was $0.16 \mathrm{~nm}$ under AFM scan of $1 \mu \mathrm{m} \times 1 \mu \mathrm{m}$. In this paper, we further present the atomic concentration and bond state of $\mathrm{B}_{4} \mathrm{C}$ coating measured by X-ray Photoelectron Spectroscopy (XPS) to serve as a guide for experimental work of boron carbide coating.

\section{EXPERIMENT}

50-nm thick boron carbide coatings were prepared by reactive sputtering with various nitrogen-argon mixture ratios. The nitrogen ratio was $4 \%, 8 \%$, and $15 \%$, respectively. During the deposition, the sputtering pressure was maintained at 1 mTorr. Further detailed information on the preparation was given in the literature [16].

The chemical states of boron, carbon, nitrogen, and oxygen in coatings were investigated by XPS. The measurements were used by Thermo Scientific ESCALAB 250Xi spectrometer with Al Ka (1486.6 eV) X-ray radiation. The etching was achieved by $10 \mathrm{~mA} 2 \mathrm{keV} \mathrm{Ar}+$ bombardment at 58 -degree grazing incidence. The etching area was $2 \mathrm{~mm} \times 2 \mathrm{~mm}$. The sensitivity factors of B $1 \mathrm{~s}, \mathrm{C} 1 \mathrm{~s}, \mathrm{~N} 1 \mathrm{~s}$, and O $1 \mathrm{~s}$ were $0.159,0.296,0.477$, and 0.711 [17]. The narrow spectra were calibrated to the $\operatorname{Ar} 2 \mathrm{p} 3 / 2$ peak $(241.9 \mathrm{eV})$ to remove the charging shift. The peak fittings were based on Shirley background and used in Gaussian-Lorentz type peaks.

\section{RESULTS AND DISCUSSION}

The atomic concentration distribution with depth profile of the coating prepared under $\mathrm{N}_{2}$ ratio of $4 \%$ was showed in Fig. 1. Close to the surface, the atomic concentrations of carbon and oxygen were 23 at. $\%$ and 18 at. $\%$, and decreased to 17 at. $\%$ and 5 at. $\%$ inside the coating. Carbon on the surface came not only from $\mathrm{B}_{4} \mathrm{C}$ coatings but also from hydrocarbon [18]. And the oxygen on the surface was most likely from water molecules [19]. The concentration of nitrogen was 18 at.\% inside the coating. Meanwhile, the $\mathrm{B} / \mathrm{C}$ ratio was $3.7: 1$.

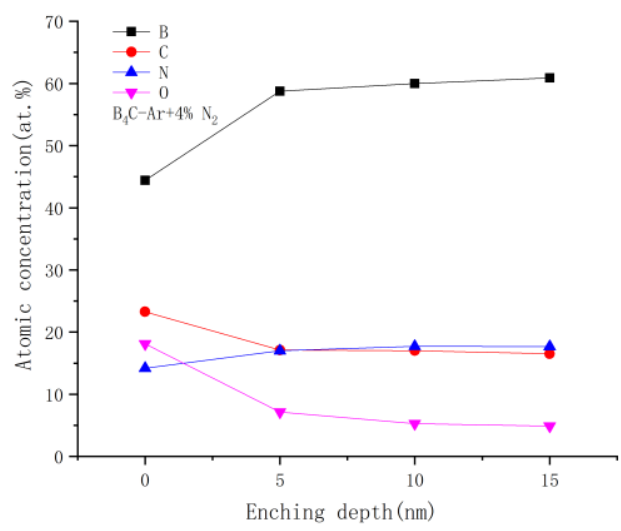

Figure 1 Atomic concentration distribution of $\mathrm{B}_{4} \mathrm{C}$ coating prepared under $\mathrm{N}_{2}$ ratio of $4 \%$

To further determine the chemical states, high-resolution spectra were showed in Fig. 2. The wide B 1s spectrum (Fig. 2a) meant multiple chemical states formed. The main peaks were at $188.6 \mathrm{eV}$ and $190.2 \mathrm{eV}$, corresponding to B-C and B-N bonds, with another peak at $189.4 \mathrm{eV}$ and $191.8 \mathrm{eV}$, corresponding to B-B and B-O bonds [17, 20-24]. It was implied that in the boron carbide coating prepared by reactive sputtering, the boron mainly existed in the formation of $\mathrm{B}_{4} \mathrm{C}$ and $\mathrm{BN}$ compounds, and some were boron element and boron oxide. The standard enthalpies of formation are $-62.7 \mathrm{~kJ} / \mathrm{mol}$, $-254.4 \mathrm{~kJ} / \mathrm{mol}$, and $-1273.5 \mathrm{~kJ} / \mathrm{mol}$, for $\mathrm{B}_{4} \mathrm{C}, \mathrm{BN}, \mathrm{B}_{2} \mathrm{O}_{3}$. Boron is easier to combine with nitrogen and oxygen to form 
chemical bonds [25].

In the $\mathrm{C} 1 \mathrm{~s}$ spectrum (Fig. 2b), there was a small peak aimed at $\mathrm{C}-\mathrm{N}$ bonds $(285.4 \mathrm{eV})$ and the main peaks were aimed at $\mathrm{B}_{4} \mathrm{C}$ icosahedron $(282.6 \mathrm{eV})$ and C-B-C triatomic chains $(283.8 \mathrm{eV})$ [26-27]. The proportion of the two states was at about 2.6:1. Inside the coating, there was no corresponding valence state indicating the presence of hydrocarbons and carbon oxides. The N 1s spectrum (Fig. 2c) was well fitted with two peaks characteristic of N-B bonds (397.8 eV) and $\mathrm{N}-\mathrm{C}$ bonds $(399.0 \mathrm{eV})$, the content of that was $83 \%$ and $16 \%$, respectively [17, 27]. It was demonstrated that the nitrogen was mainly reacted with boron rather than carbon. Although the deposition environment was in ultra-high vacuum, a few oxygens existed in the coating. The main peak in the O $1 \mathrm{~s}$ spectrum (Fig. 2d) was at $532.0 \mathrm{eV}$ with a content of $53 \%$, corresponding to boron oxide [17, 28]. The other peak was aimed at carbon oxide [28].
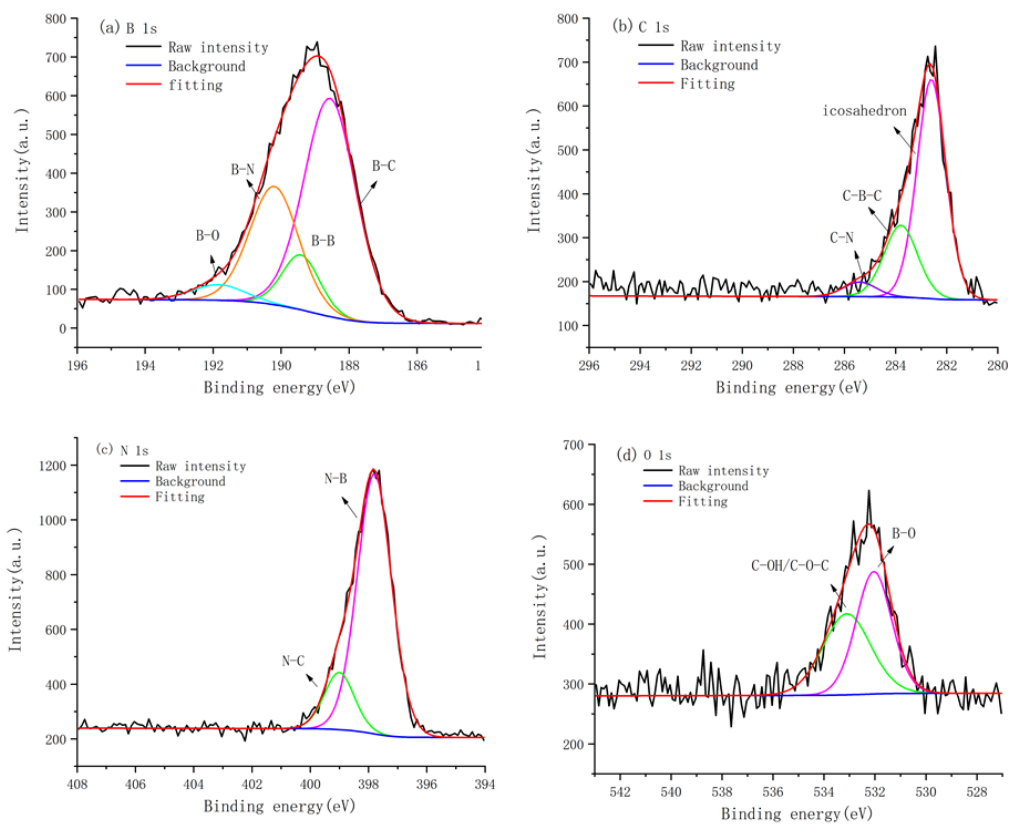

Figure 2 The B 1s (a), C 1s (b), N 1s (c) and O1s (d) spectra in the coating with $\mathrm{N}_{2}$ ratio of $4 \%$

Fig. 3 presented the $\mathrm{B} / \mathrm{C}$ atomic ratio and $\mathrm{N} / \mathrm{C}$ atomic ratio in the $\mathrm{B}_{4} \mathrm{C}$ coatings with different nitrogen-argon mixture gas, including with pure argon gas. The B/C atomic ratio, calculated from the quantification of XPS spectra, decreased from 4.6:1 to 3.3:1 with the increase of $\mathrm{N}_{2}$ ratio in the sputtering gas. The $\mathrm{N} / \mathrm{C}$ atomic ratio showed the contrast trend.

The $\mathrm{B}$ 1s spectra in the $\mathrm{B}_{4} \mathrm{C}$ coatings with different nitrogen-argon mixture gas were showed in Fig. 4. It was presented that the $\mathrm{B} 1 \mathrm{~s}$ spectrum was shifted to the higher binding energy with the increase of $\mathrm{N}_{2}$ ratio in the sputtering gas. Compared with pure $\mathrm{B}_{4} \mathrm{C}$ coatings, $\mathrm{B}-\mathrm{N}$ bonds were found in nitridated $\mathrm{B}_{4} \mathrm{C}$ coatings and their content increased with the increase of $\mathrm{N}_{2}$ ratio in mixture gas. When the nitrogen ratio was $4 \%, 8 \%, 15 \%$, the content of $\mathrm{B}-\mathrm{N}$ bonds in the $\mathrm{B} 1 \mathrm{~s}$ spectrum was $29 \%, 59 \%, 80 \%$, respectively. For $\mathrm{B}_{4} \mathrm{C}$ coatings prepared by reactive sputtering with nitrogen, the chemical environment and the bonding structure of boron atoms have changed. 


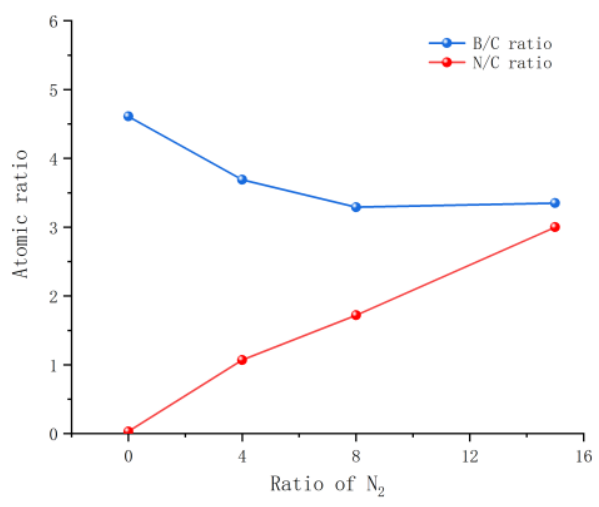

Figure 3 The $\mathrm{B} / \mathrm{C}$ atomic ratio and N/C atomic ratio in the $\mathrm{B} 4 \mathrm{C}$ coatings with different nitrogen-argon mixture gas

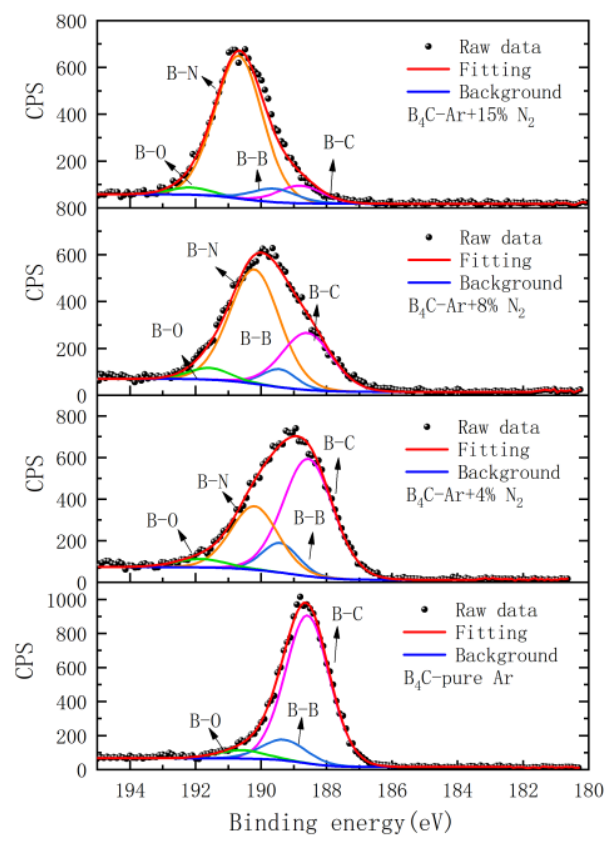

Figure 4 The $\mathrm{B}$ 1s spectra in the $\mathrm{B}_{4} \mathrm{C}$ coatings with different nitrogen-argon mixture gas

Elemental absorption edges existed in the soft X-ray range would cause the decrease of reflectivity. Assuming the surface roughness of $0.5 \mathrm{~nm}$ and using the atomic stoichiometric ratio calculated from XPS spectra, the theoretical reflectivity of $50-\mathrm{nm}$ thick $\mathrm{B}_{4} \mathrm{C}$ coatings with different nitrogen-argon mixture gas were calculated by IMD software (Fig. 5). In the energy range from 0.1 to $3 \mathrm{keV}$ and at grazing angle of 0.57 degree, the theoretical reflectivity of nitridated $\mathrm{B}_{4} \mathrm{C}$ coatings decreased near the boron, carbon, nitrogen and oxygen $K$-edge of absorption. The effect of the nitrogen absorption edge on the reflectivity was more serious than that of boron absorption edge, resulting in sharp decrease of reflectivity near $410 \mathrm{eV}$. 


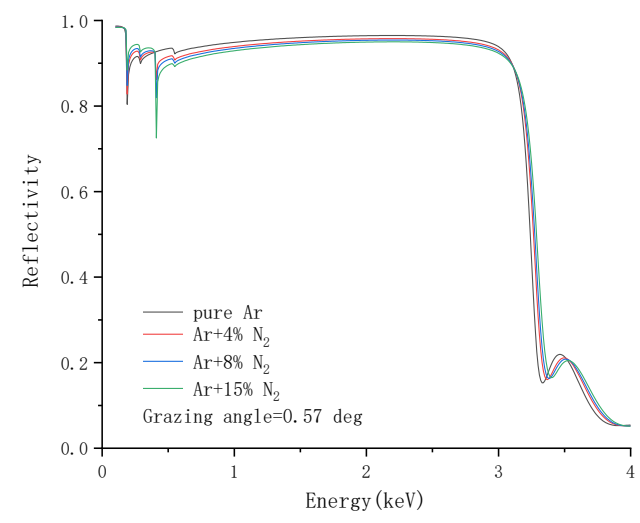

Figure 5 The theoretical reflectivity of $\mathrm{B}_{4} \mathrm{C}$ coating in the soft X-ray

\section{CONCLUSION}

XPS was used (see also Sects. 3-4 [29]) to investigate the chemical states of a series of reactively-sputtered $\mathrm{B}_{4} \mathrm{C}$ coatings. As the $\mathrm{N}_{2}$ ratio of $4 \%$ in the sputtering gas, the $\mathrm{B} / \mathrm{C}$ ratio was $3.7: 1$ and the nitrogen content was 18 at.\% in the coating. Compared with $\mathrm{B}_{4} \mathrm{C}$ coatings, the boron in nitridated $\mathrm{B}_{4} \mathrm{C}$ coatings mainly forms chemical bonds with nitrogen and carbon, corresponding to $\mathrm{BN}$ and $\mathrm{B}_{4} \mathrm{C}$ compounds. The nitrogen incorporated in the coatings is preferentially bonded to boron atoms instead of carbon atoms. With the increase $\mathrm{N}_{2}$ ratio in sputtering gas, nitrogen content in the coating was increase while the $\mathrm{B} / \mathrm{C}$ ratio was reduced to 3.3:1. In the theoretical reflectivity, the increase of nitrogen content decreased the reflectivity of soft X-ray, especially around $410 \mathrm{eV}$. Taking account into the coating stress and theoretical reflectivity, the $\mathrm{B}_{4} \mathrm{C}$ coating under the $\mathrm{N}_{2}$ ratio of $4 \%$ is suitable for application and its damage threshold would be further studied.

\section{REFERENCES}

[1] Störmer M, Horstmann C, Siewert F, et al. Single-layer mirrors for advanced research light sources[J]. AIP Conference Proceedings, 2010, 1234;756-759.

[2] Pivovaroff M J, Bionta R M, Mccarville T J, et al. Soft X-ray mirrors for the Linac Coherent Light Source[J]. Proceedings of SPIE, 2007, 6705:67050O.

[3] Hau-Riege S P, London R A, Graf A, et al. Interaction of short X-ray pulses with low-Z X-ray optics materials at the LCLS free-electron laser[J]. Optics Express, 2010, 18(23):23933-23938.

[4] Hau-Riege S P, London R A, Bionta R M, et al. Damage threshold of inorganic solids under free-electron-laser irradiation at 32.5nm wavelength[J]. Applied Physics Letters, 2007, 90(173128)

[5] Soufli R, Pivovaroff M J, Baker S L, et al. Development, characterization and experimental performance of X-ray optics for the LCLS free-electron laser[J]. Proceedings of SPIE, 2008, 7077:707716.

[6] Follath R, Flechsig U, Milne C, et al. Optical design of the ARAMIS-beamlines at SwissFEL[J]. AIP Conference Proceedings, 2016, 1741;020009-020009-4

[7] Milne C J, Schietinger T, Aiba M, et al. SwissFEL: The Swiss X-ray Free Electron Laser[J]. Applied Sciences, 2017, 7(7):720.

[8] Morawe C, Peffen J C, Friedrich K. In-situ stress measurements of sputtered multilayers[J]. Proceedings of SPIE, 2010, 7802:78020B-78020B-14.

[9] Niibe M, Nii H, Sugie Y. Stress Changes and Stability of Sputter-Deposited Mo/B $\mathrm{B}_{4} \mathrm{C}$ Multilayer Films for Extreme Ultraviolet Mirrors[J]. Japanese Journal of Applied Physics, 2002, 41(Part 1, No. 5A):3069-3075.

[10] Wang Y, Huang Q, Yi Q, et al. Nitridated $\mathrm{Pd} / \mathrm{B}_{4} \mathrm{C}$ multilayer mirrors for soft X-ray region: internal structure and aging effects[J]. Optics Express, 2017, 25(7);7749-7760.

[11] Kulikovsky V, Vorlicek V, Ctvrtlik R, et al. Effect of air annealing on mechanical properties and structure of amorphous B4C films[J]. Surface \& Coatings Technology, 2011, 205(16):4052-4057.

[12] Soufli R, Baker S L, Robinson J C, et al. Morphology, microstructure, stress and damage properties of thin film coatings for the LCLS x-ray mirrors[J]. Proceedings of SPIE, 2009, 7361;73610U. 
[13] Windt D L. Reduction of stress and roughness by reactive sputtering in $\mathrm{W} / \mathrm{B}_{4} \mathrm{C}$ multilayer films[J]. 2007.6688;66880R.

[14] Laidani N, Anderle M, Canteri R, et al. Structural and compositional study of B-C-N films produced by laser ablation of $\mathrm{B}_{4} \mathrm{C}$ targets in $\mathrm{N}_{2}$ atmosphere[J]. Applied Surface Science, 2000, 157(3):135-144.

[15] Bengu E, Genisel M F, Gulseren O, et al. Theoretical and spectroscopic investigations on the structure and bonding in B-C-N thin films, ScienceDirect[J]. Thin Solid Films, 2009, 518( 5):1459-1464.

[16] Wu J, Qi R, Huang Q, et al. Stress, Roughness and Reflectivity Properties of Sputter-Deposited $\mathrm{B}_{4} \mathrm{C}$ Coatings for X-Ray Mirrors[J]. Chinese Physics Letters, 2019, 36(12):120701.

[17] Moulder J F, Handbook of X-ray photoelectron spectroscopy: a reference book of standard spectra for identification and interpretation of XPS data[M]. Eden Prairie, MN, 1995.

[18] $\mathrm{Hu}$ T, Steihl L, Rafaniello W, et al. Structures and properties of disordered boron carbide coatings generated by magnetron sputtering[J]. Thin Solid Films, 1998, 332(1-2):80-86.

[19] Kozhevnikov I V, Filatova E O, Sokolov A A, et al. Comparative study of the X-ray reflectivity and in-depth profile of a-C, B4C and Ni coatings at 0.1-2keV[J]. Journal of Synchrotron Radiation, 2015, 22;348-353.

[20] Jacobsohn L G, et al. X-ray photoelectron spectroscopy investigation of boron carbide films deposited by sputtering[J]. Surface Science, 2004, 572(2-3):418-424.

[21] Soufli R, Aquila A L, Salmassi F, et al. Optical constants of magnetron-sputtered boron carbide thin films from photo absorption data in the range 30 to $770 \mathrm{eV}[\mathrm{J}]$. Applied Optics, 2008, 47(25):4633-4639.

[22] Huang Q, Liu $\mathrm{Y}$, Yang $\mathrm{Y}$, et al. Nitridated Ru/ $\mathrm{B}_{4} \mathrm{C}$ multilayer mirrors with improved interface structure, zero stress, and enhanced hard X-ray reflectance[J]. Optics Express, 2018, 26(17):21803.

[23] https://srdata.nist.gov/xps/selEnergyType.aspx (NIST XPS Database).

[24] Laidani N, Anderle M, Canteri R, et al. Structural and compositional study of B-C-N films produced by laser ablation of $\mathrm{B}_{4} \mathrm{C}$ targets in $\mathrm{N}_{2}$ atmosphere[J]. Applied Surface Science, 2000, 157(3):135-144.

[25] Speight J G, Lange N A . Lange's Handbook of Chemistry, 16 ed[M]. McGraw-Hill, 1973.

[26] Zhou M J, Wong S F, Ong C W, et al. Microstructure and mechanical properties of $\mathrm{B}_{4} \mathrm{C}$ films deposited by ion beam sputtering[J]. Thin Solid Films, 2007, 516(2-4):336-339.

[27] Prakash A, Sundaram K B. Optical and XPS studies of BCN thin films by co-sputtering of $\mathrm{B}_{4} \mathrm{C}$ and $\mathrm{BN}$ targets[J]. Applied Surface Science, 2016, 396:484-491.

[28] Jacobsohn L G, et al. X-ray photoelectron spectroscopy investigation of boron carbide films deposited by sputtering[J]. Surface Science, 2004, 572(2-3):418-424.

[29] D. Bleiner, The Science and Technology of X-ray Lasers: A 2020 Update Proc. SPIE 11886, 1188602 (2021) 